\title{
O BULLYING ESCOLAR NO CONTRAMÃO DA EDUCAÇÃO INCLUSIVA: CONSIDERAÇÕES PRELIMINARES SOBRE A REALIDADE DO ENSINO MÉDIO EM SÃO RAIMUNDO NONATO - PIAUÍ
}

\author{
THE SCHOOL BULLYING IN THE CONTROVERSY OF INCLUSIVE EDUCATION: \\ PRELIMINARY CONSIDERATIONS ABOUT THE REALITY OF A MIDDLE SCHOOL IN \\ SÃO RAIMUNDO NONATO - PIAUÍ
}

\section{Alex Dias De Jesus INSTITUTO FEDERAL DO PIAUÍ}

\begin{abstract}
RESUMO: O bullying escolar, enquanto uma das manifestações da violência, lamentavelmente está presente em muitos estabelecimentos de ensino, atravessando diferentes estratos sociais, regiões geográficas e tamanho das escolas. Diante disso, torna-se importante o conhecimento dessa realidade, o debate de ideias e a formação profissional como etapas iniciais de ações de combate ao fenômeno em questão. Por esse motivo, esta pesquisa tem como objetivos apresentar algumas considerações histórico conceituais sobre o assunto, bem como analisar a possível exposição à violência de jovens e adolescentes da cidade de São Raimundo Nonato, Piauí. Para tanto, a metodologia baseou-se em levantamento bibliográfico e aplicação de questionário online ${ }^{1}$ contendo questões relacionadas à temática aqui discutida.
\end{abstract}

Palavras-chave: Bullying. Educação Inclusiva. São Raimundo Nonato-PI.

\begin{abstract}
The school bullying, as an of the manifestations of violence, is sadly present in many schools across different social stratum, geographic regions and school size. Given this, it becomes important to know this reality, the debate of ideas and professional training as initial stages of actions to combat the phenomenon in question. For this reason, this research has the objectives to present some conceptual historical considerations on the subject, as well as to analyze the possible exposure to violence of young people and adolescents of the city of São Raimundo Nonato, Piauí. For this, the methodology was based in bibliographical survey and application of an online questionnaire containing questions related to the subject matter discussed here.
\end{abstract}

Key words: Bullying. Inclusive education. São Raimundo Nonato-PI.

\footnotetext{
${ }^{1} \mathrm{O}$ autor agradece aos estudantes Gabriell Oliveira e Sunamita Ribeiro pela valiosa contribuição na elaboração e divulgação do questionário.
} 


\section{ASPECTOS GERAIS DO BULLYING EM AMBIENTE ESCOLAR}

O bullying, palavra de origem inglesa utilizada para caracterizar atitudes de violência física e psicológica de maneira repetitiva e intencional, não possui tradução para o português mas teve seu uso generalizado na última década. Tentando uma aproximação com a realidade brasileira, o ordenamento jurídico do país passou a considerar tais atos como intimidação sistemática, mesmo que ocorridas de maneiras variadas, mas que refletem formas de violência, sobretudo no ambiente escolar.

O termo deriva de bully, indivíduo valentão, tirano, brigão, ou seja, um agressor que, geralmente sem motivação aparente, pratica atos de violência física e psicológica contra uma ou mais vítimas impossibilitadas de se defender por circunstâncias diversas. Tratadas quase sempre como brincadeiras, as ações podem ocorrer como agressões, perseguições, ameaças, intimidações, isolamento social, dentre outras. De acordo com SILVA $(2010)^{2}$, brincadeiras ocorrem de forma natural e espontânea entre alunos, como piadas e apelidos, mas quando isso se transforma em atos de violência e quando apenas alguns se divertem às custas dos outros, isso recebe o nome de bullying escolar.

Embora as diversas formas de agressões há muito tempo façam parte do ambiente escolar, apenas na década de 1970, na Suécia, esse fato começou a ganhar a atenção diante do aumento da violência entre estudantes e suas consequências no âmbito da educação formal. No mesmo período, na Noruega, pais e professores começaram a publicizar temores e angústias sobre os acontecimentos, mas sem atenção devida das autoridades educacionais (SILVA, 2010). O suicídio de três crianças, com idade entre 10 e 14 anos no norte daquele país, talvez tenha sido o estopim para que o problema fosse visto com maior atenção e preocupação.

As investigações do caso apontaram, como principal motivação da tragédia, as situações de maus tratos a que tais jovens foram submetidos por seus colegas de escola. Em resposta à grande mobilização nacional diante dos fatos, o Ministério da Educação da Noruega realizou, em 1983, uma campanha em larga escala, visando ao combate efetivo do bullying escolar (SILVA, 2010, p. 111).

\footnotetext{
${ }^{2}$ SILVA, Ana Beatriz Barbosa. Bullying: mentes perigosas nas escolas. Rio de Janeiro: Objetiva, 2010.
} 
Desde 1978, Dan Olweus, pesquisador da Universidade de Berger na Noruega, já pesquisava sobre o assunto, mas esses fatos o impulsionaram a ampliar suas pesquisas em abrangência e profundidade. Durante anos, o estudo de Olweus envolveu 84 mil estudantes, quase quatrocentos professores e cerca de mil pais de alunos com o objetivo de avaliar as taxas de ocorrência e as formas pelas quais 0 bullying se realizava. A pesquisa constatou que um em cada sete estudantes encontrava-se envolvido em casos de bullying seja como vítima ou como agressor. Esses resultados originaram uma campanha nacional antibullying que recebeu amplo apoio do governo norueguês (SILVA, 2010).

Como consequência, houve a diminuição da violência escolar em $50 \%$ no país. Isso estimulou outros países como Inglaterra, Canadá e Portugal a realizarem campanhas semelhantes. Em todo o mundo a violência escolar é observada, variando as formas e intensidades de sua manifestação. De acordo com Silva (2010, p. 112), "estima-se que de $5 \%$ a $35 \%$ das crianças em idade escolar estejam envolvidas em condutas agressivas no ambiente educacional". Soma-se ainda aqueles que são testemunhas, mas que permanecem calados por conivência ou medo.

A partir da década de 1990 intensificou-se o trabalho sobre o bullying em diversos países, principalmente pesquisas e campanhas de combate ao fenômeno tanto por instituições privadas quanto governamentais. No Brasil, desde 2001, a Associação Brasileira Multiprofissional de Proteção à Infância e Adolescência (ABRAPIA), dedica-se a pesquisar e divulgar o assunto. Uma de suas primeiras pesquisas, realizada entre 2002 e 2003 e tendo como foco o estado do Rio de Janeiro, revelou que $40,5 \%$ dos estudantes entrevistados admitiram ter tido algum envolvimento na prática de bullying, seja como vítima ou como agressor (SILVA, 2010).

Um dos mais famosos programas de combate ao bullying do mundo e talvez 0 que mais resultados positivos apresentou foi o finlandês "Kiusaamista Vastaan" KiVa que significa "Contra o Bullying" em livre tradução. Como grande parte das agressões conta com espectadores, o KiVa estimula a intervenção das testemunhas, melhorando o convívio escolar. Enquanto a maioria dos projetos são direcionados às vítimas e aos autores, o programa finlandês adotou metodologia diferenciada, 
alcançando melhores resultados, sendo inclusive exportado para mais de 20 países (BERNARDO, 2017) ${ }^{3}$.

Em 2016, a pesquisa "Diagnóstico participativo das violências nas escolas: falam os jovens", coordenada por Abramovay $(2016)^{4}$, apontou que a violência física ou verbal atingiu $42 \%$ dos estudantes da rede pública brasileira. Entre as vítimas, $65 \%$ apontou um colega como agressor. As salas de aula e os pátios são os principais locais de ocorrência das ações. Cyberbullying, furto ou roubo e ameaças são as formas mais recorrentes. Embora a pesquisa não aponte exatamente a exposição e/ou vitimização prolongada de crianças e adolescentes à violência, tendo em vista que ela pode ter ocorrido apenas uma vez, ela é um importante termômetro para analisar que as agressões são variadas e que por isso demandam estratégias múltiplas no seu combate.

Segundo Silva (2010), um número cada vez maior de denúncias relativas às práticas de bullying tem sido recebido nas Varas da Infância e da Adolescência e o que chama atenção é que a quase totalidade das denúncias é relativa a agressões ocorridas em escolas públicas. Uma análise apressada poderia indicar que as escolas particulares são seguras e que seus estudantes não vivenciam situações de violência física e psicológica. Todavia, a autora alerta para uma realidade preocupante: muitas escolas particulares silenciam os casos com medo de perderem "clientes". Assim, a omissão dificulta e até impede as ações preventivas que poderiam coibir o problema.

No Brasil, alguns casos extremos de violência foram praticados por jovens e adolescentes outrora vítimas de bullying em suas escolas. Em 2003, na cidade de Taiuva-SP, um jovem de 18 anos entrou na escola que havia concluído o ensino médio, disparou contra 50 pessoas, feriu oito e se matou em seguida. Em 2004, na cidade de Remanso-BA, outro jovem de 17 anos matou duas pessoas, feriu mais três e tentou suicídio. No Rio de Janeiro, em 2011, um jovem de 23 anos matou doze crianças e feriu mais treze em sua antiga escola, no que ficou conhecido como "Massacre de Realengo. Mais recentemente, em 2017, um adolescente de 14 anos

\footnotetext{
${ }^{3}$ BERNARDO, André. BBC Brasil. De notas baixas a depressão na vida adulta, as marcas do bullying em agredidos e agressores Disponível em: http://www.bbc.com/portuguese/brasil$\underline{41689223}$ Acesso feito em 13 de janeiro de 2018.

${ }^{4}$ ABRAMOVAY, Miriam. (Coord.). Diagnóstico participativo das violências nas escolas: falam os jovens. Rio de Janeiro: FLACSO - Brasil, OEI, MEC, 2016.
} 
matou dois colegas e feriu quatro, na cidade de Goiânia-GO. Em todos os casos, os agressores haviam sido vítimas de violência repetidas vezes.

Dificilmente as vítimas sofrem apenas um tipo de agressão. Geralmente são manifestações conjuntas, envolvendo alguns tipos de maus tratos, mesmo se for apenas um agressor. A variedade de formas de violência contribui para a exclusão social da vítima, para a evasão escolar, podendo ampliar suas consequências para as relações extraescolares. Por algum motivo, sempre injustificável, as vítimas são submetidas à agressões que podem marcar profundamente suas vidas.

De acordo com Silva (2010), o bullying assume variadas formas: o verbal, que compreende os insultos, ofensas, xingamentos, gozações, apelidos pejorativos, piadas ofensivas, dentre outras. O físico e material são agressões como chutes, socos, empurrões, roubo, furto ou destruição dos pertences das vítimas. O psicológico e moral constitui-se em humilhar, ridicularizar, excluir, isolar, ignorar, discriminar, chantagear, ameaçar, perseguir e tantas outras atitudes. Já o sexual, mais comum entre meninos e meninas e entre meninos, consiste em abusar, violentar, assediar e insinuar.

Tipicamente, as vítimas são estudantes que não se enquadram nos padrões estéticos normatizados ou possuem alguma marca que as destaca da maioria, alguma deficiência ou ainda aqueles que são tímidos ou reservados. Desse modo, aquele aluno gordo ou magro demais, mais alto ou mais baixo, aquele que usa óculos, que possui sardas na pele, que usa roupas fora de moda, que é gay... enfim, qualquer coisa pode torná-lo vítima de bullying, os motivos são os mais banais possíveis.

Normalmente, essas crianças ou adolescentes "estampam" facilmente as suas inseguranças na forma de extrema sensibilidade, passividade, submissão, falta de coordenação motora, baixa autoestima, ansiedade excessiva, dificuldade de se expressar. Por apresentarem dificuldades significativas de se impor ao grupo, tanto física quanto verbalmente, tornam-se alvos fáceis e comuns dos ofensores (SILVA, 2010, p. 38).

Quanto aos agressores, geralmente exercem poder de liderança sobre outros o que faz suas atitudes ganharem amplitude. É comum que essa liderança seja obtida por meio da força física ou de intenso assédio psicológico. Apresentam desrespeito e covardia e têm dificuldades em seguir normas e regras. Não aceitam 
ser contrariados, frustrados e apresentam pouca sensibilidade diante do sofrimento alheio. As causas para esses comportamentos podem estar no próprio temperamento do jovem, mas em muitos casos estão associadas à exposição frequente à violência em casa, na vizinhança ou até mesmo no mundo virtual.

Há ainda os observadores que testemunham a ação dos agressores contra as vítimas que mas não saem em defesa delas e nem se juntam aos primeiros. Podem ser passivos, que permanecem calados por medo de também se transformarem em vítimas. Mesmo repudiando as atitudes, não conseguem agir em defesa delas. Podem também ser ativos, manifestando apoio moral com risadas ou palavras de incentivo, não se envolvem diretamente, mas podem se divertir com as agressões. $E$ há também os observadores neutros, aqueles que não demonstram sensibilidade diante dos fatos, não estimulam, mas também não se compadecem.

As reações aos diversos tipos de violência variam de pessoa para pessoa em virtude dos condicionantes genéticos e do meio social onde está inserido. Desse modo, pode haver pessoas que mesmo sendo expostas à frequentes situações de violência sejam pouco afetadas por ela, levando uma vida dentro dos padrões de normalidade. Contudo, Silva (2010) aponta que é mais frequente observar que crianças e adolescentes envolvidas em meio ao bullying desenvolvem reações estimuladas por ele. Alguns tornam-se resilientes, encorajados e conseguem transformar o sofrimento em aprendizado, a dor em superação. Outros carregam consigo os traumas da vitimização por muito tempo, tornando-se adultos inseguros, ansiosos ou mesmo depressivos e agressivos. Outros ainda podem desenvolver transtornos psiquiátricos sérios como depressão, pânico, psicoses, etc.

Mais grave ainda quando os atos de violência são cometidos contra crianças e adolescentes com algum tipo de deficiência, seja física ou mental. As crianças que apresentam transtorno do desenvolvimento, como o autismo, tendem a sofrer agravamento dos sintomas, dificultando ainda mais a inserção no ambiente escolar e, por extensão, na sociedade.

Segundo Martinez $(2013)^{5}$, os agressores também somam as consequências do bullying em seus aprendizados ao incorporar a fórmula da impunidade diante dos seus atos o que pode contribuir seriamente para a delinquência futura. Alguns

\footnotetext{
${ }^{5}$ MARTÍNEZ, José Maria Avilés. Bullying: guia para educadores. Tradução de J. Guillermo MilánRamos. Campinas: Mercado de Letras, 2013.
} 
reproduzem esses comportamentos em suas relações de trabalho e familiares, chegando a incorporar, entre suas ferramentas, sofisticadas habilidades de manipulação a seu favor.

Como geralmente as pesquisas e intervenções estão focadas nas vítimas e nos agressores, pouco se fala a respeito das consequências nas testemunhas. Porém, Martinez adverte:

Falamos de uma série de sensações variadas que vão desde a indiferença, a dessensibilização e a incompreensão até a indefensibilidade, a ansiedade e a culpabilidade. Basicamente falamos de que aquele que contempla uma situação tão injusta, sabendo que o é, acostuma-se com isso, a olhar para outro lugar, a suportá-la e a estabelecer uma sorte de relação à distância, também insana com quem tem poder e o exerce abusivamente sobre outros (MARTINEZ, 2013, p. 53).

Nem sempre a violência pode ser considerada bullying ou, como normatizado pelo ordenamento jurídico brasileiro, intimidação sistemática. Para que se configure dessa forma as agressões devem apresentar a natureza repetitiva em um contexto de desequilíbrio de poder, o que impede que a vítima reaja, aumentando assim sua vulnerabilidade diante do agressor. Tentando contribuir na identificação dos casos, Martinez (2013) aponta alguns componentes frequentes do bullying como a intencionalidade, a humilhação, o silêncio perante os adultos, a exculpação, a invisibilidade, a recorrência, a indefensabilidade, a gratuidade, dentre outros.

Entretanto, em alguns casos, mesmo que a conduta não seja tipificada como bullying, dependendo da gravidade, uma ou duas atitudes com potencial hostil podem gerar consequências emocionais extremamente desagradáveis e atrapalhar o processo de aprendizagem. É o caso, por exemplo, de um trote universitário ou uma ridicularização enquanto um aluno apresenta um trabalho. A piada que parece banal naquele momento pode voltar à memória toda vez que o estudante se encontrar em situação semelhante. Como consequência, a vítima afetada tende ao máximo evitar situações em que possa ser alvo de constrangimentos e humilhações, deixando de fazer perguntas aos professores, evitando emitir opiniões ou agir de maneira natural frente aos colegas. "Tomada por sentimentos de ansiedade, angústia e tensão, a vítima prefere calar-se ou isolar-se dos demais, como forma de minimizar seu sofrimento" (SILVA, 2010, p. 152). 
Dias e Pingoello $(2016)^{6}$ discutem ações de bullying diante de alunos que apresentam necessidades educacionais especiais e apontam os prejuízos que as agressões podem causar dentro do processo de educação inclusiva. Para as autoras, tais estudantes enfrentam uma dupla batalha no cotidiano escolar: o enfrentamento das dificuldades decorrentes de sua deficiência e a discriminação daqueles que os julgam como incapaz, causando isolamento, dificuldades de inclusão, de aprendizagem e às vezes regressão em casos clínicos.

\begin{abstract}
As crianças com deficiência que sofrem bullying, bem como a própria discriminação e preconceito na escola, são excluídas da interação social com os outros alunos, o que prejudica seu desenvolvimento e sua aprendizagem, e o que acaba caracterizando a inclusão excludente. A escola é responsável por essa mediação do processo de desenvolvimento dos indivíduos, tornando-se por esse motivo, necessário que professores, bem como toda a equipe, saibam identificar o bullying escolar e planejar formas de prevenir essa violência contra esses alunos (DIAS e PINGOELLO, 2016, p. 41).
\end{abstract}

Aprendizagem e desenvolvimento são processos indissociáveis e fazem parte das relações sociais. Por essa razão, o isolamento social, marcado pelo medo e insegurança originados do bullying trazem prejuízos consideráveis ao desenvolvimento cognitivo. Como as instituições sociais nas quais crianças e adolescentes estão inseridos funcionam como mediadoras desse processo, a saber: família, escola, igreja, etc., cabe a elas maior atenção e, se necessário, intervenção.

Importa destacar que a educação inclusiva não limita-se aos estudantes portadores de necessidades físicas e educacionais especiais, abrangendo também outros grupos que historicamente sofreram e ainda sofrem discriminações. Seu objetivo maior é proporcionar educação de maneira igualitária e universal, considerando a multiplicidade de características que envolvem seus sujeitos. $\mathrm{O}$ acesso de todos à escola comum, sem discriminação, é um direito que deve ser garantido em todos os lugares. No Brasil, a Constituição Federal de $1988^{7}$ preconiza o direito universal à educação, tendo um dos seus princípios a igualdade de

\footnotetext{
${ }^{6}$ DIAS, Fabiana Bruna Gozer e PINGOELLO, Ivone. Bullying na Educação Inclusiva. Revista de Educação do Vale do Arinos, Juara/MT/Brasil, v. 3, n. 1, jan./Jul. 2016, p. 40-54.

7 BRASIL. Constituição da República Federativa do Brasil. Brasília, 1988. Disponível em: http://www.planalto.gov.br/ccivil 03/constituicao/constituicaocompilado.htm Acesso feito em 16 de janeiro de 2018.
} 
condições para o acesso e permanência na escola, conforme disposto em seu Art. 206, inciso I. Já a Lei de Diretrizes e Bases da Educação (Lei 9.394/96) ${ }^{8}$ dispõe, em seu Art. 3, inciso IV, que a educação também pauta-se no respeito à liberdade e apreço à tolerância. O Estatuto da Criança e do Adolescente (Lei 8.069/90) ${ }^{9}$, em seu Art. 53, reforça que a educação visa o pleno desenvolvimento da criança e do adolescente. Por fim, a Lei $13.185 / 2015^{10}$ institui o Programa de Combate à Intimidação Sistemática (Bullying).

Citamos a legislação relacionada ao tema para reforçar que os processos educativos formais devem ser garantidos pelo Estado em condições favoráveis ao pleno desenvolvimento dos estudantes. Deriva-se daí a necessidade de ambientes salubres e seguros à sua integridade física e psicológica. Todavia, são frequentes os casos em que essas condições não são satisfeitas dificultando ou impedindo que a educação seja de fato inclusiva. Apenas para exemplificar, Vieira et al (2015) ${ }^{11}$ afirmam que a população LGBT apresenta maiores taxas de evasão escolar pois as suas diferenças são transformadas em desigualdades.

As pessoas que não se submetem aos padrões de feminilidades, masculinidades e orientações sexuais encarados como normais, a partir da ótica dos padrões sociais dominantes, são reiteradamente expostas, no ambiente escolar, à violações de direitos, agressões físicas e verbais e discriminações de todo tipo. Suas diferenças convertem-se em reais desigualdades (VIEIRA et al, 2015, p. 1).

Como apontamos, os motivos para que alguém seja escolhido enquanto vítima são sempre injustificáveis e alguns grupos, em determinados contextos,

\footnotetext{
${ }^{8}$ BRASIL. Lei 9.394 de 20 de dezembro de 1996. Lei de Diretrizes e Bases da Educação Nacional. Brasília, 1996. Disponível em: http://www.planalto.gov.br/ccivil 03/leis/L9394.htm Acesso feito em 16 de janeiro de 2018.

${ }^{9}$ BRASIL. Lei 8.069 de 13 de julho de 1990. Estatuto da Criança e do Adolescente. Brasília, 1990. Disponível em: http://www.planalto.gov.br/ccivil 03/leis/L8069.htm Acesso feito em 16 de janeiro de 2018.

${ }^{10}$ BRASIL. Lei 13.185 de 6 de novembro de 2015. Institui o Programa de Combate à Intimidação Sistemática. Disponível em: http://www.planalto.gov.br/ccivil 03/ ato2015-2018/2015/lei//13185.htm Acesso feito em 16 de janeiro de 2018.

${ }^{11}$ VIEIRA, Vanessa Alves et al. Gênero e diversidade sexual nas escolas: uma questão de direitos humanos. Carta Capital, 2015. Disponível em: https://www.cartacapital.com.br/sociedade/genero-ediversidade-sexual-nas-escolas-uma-questao-de-direitos-humanos-6727.html Acesso feito em 16 de janeiro de 2018.
} 
sofrem mais que outros. De toda forma, ressalta-se que as ações de intimidação sistemática são inaceitáveis e seu combate é emergencial. Para isso, a atuação conjunta de diversos sujeitos próximos é fundamental na identificação dos envolvidos e na resolução da questão. Silva (2010) argumenta que identificar os alunos que são vítimas, agressores ou espectadores é fundamental para que as escolas e as famílias dos envolvidos possam elaborar estratégias e traçar ações efetivas.

Quadro 1. Alguns comportamentos típicos de crianças e adolescentes expostos ao bullying

\begin{tabular}{|c|c|c|}
\hline & No ambiente escolar & No ambiente doméstico \\
\hline Vítimas & $\begin{array}{l}\text { *Isolamento do grupo. } \\
\text { *Proximidade com adultos em } \\
\text { busca de proteção. } \\
\text { *Postura retraída. } \\
\text { *Últimas a serem escolhidas em } \\
\text { atividades grupais. } \\
\text { *Faltas frequentes } \\
\text { desinteresse gradativo. } \\
\text { *Tristeza, aflição, dentre } \\
\text { outros... }\end{array}$ & $\begin{array}{l}\text { *Queixas frequentes de dores de } \\
\text { cabeça, enjoos, tonturas, } \\
\text { insônia. } \\
\text { *Poucos amigos. } \\
\text { *Mudanças repentinas no } \\
\text { humor. } \\
\text { *Desculpas para não ir às aulas. } \\
\text { *Tornam-se descuidadas com os } \\
\text { afazeres escolares. }\end{array}$ \\
\hline Agressores & $\begin{array}{l}{ }^{*} \text { Realizam brincadeiras de mau } \\
\text { gosto com colegas. } \\
{ }^{\star} \text { Frequentemente } \\
\text { menosprezam, constrangem e } \\
\text { ridicularizam os demais. } \\
\text { *Estão sempre envolvidos em } \\
\text { desentendimentos na turma. } \\
{ }^{*} \text { Agridem fisicamente os mais } \\
\text { frágeis. } \\
{ }^{*} \text { Roubam ou furtam objetos dos } \\
\text { colegas. }\end{array}$ & $\begin{array}{l}\text { *Apresentam atitudes hostis, } \\
\text { desafiadoras e agressivas. } \\
\text { *Não respeitam hierarquias. } \\
\text { *Mostram habilidades em } \\
\text { manipulação. } \\
\text { *Podem vestir-se e portar-se de } \\
\text { maneira afrontosa. } \\
\text { *Aparecem com objetos e } \\
\text { dinheiro sem explicar a origem. }\end{array}$ \\
\hline Espectadores & \multicolumn{2}{|c|}{$\begin{array}{l}{ }^{*} \text { Em ambos os ambientes tendem a manterem-se calados sobre o } \\
\text { que viram ou ouviram. } \\
{ }^{\star} \text { Os mais ansiosos ou sensíveis contam histórias mas negam que } \\
\text { sejam próximas. }\end{array}$} \\
\hline
\end{tabular}

Fonte: elaboração própria com base em SILVA, 2010. 
Longe de apresentar um manual, o quadro traz alguns comportamentos que são frequentes naqueles expostos à situações de agressão. A autora baseia-se na recorrência dos casos clínicos que acompanha, bem como em outras pesquisas que apontam características semelhantes. Um mecanismo de "escuta" anônima pode ser uma boa estratégia para o começo do diagnóstico e foi isso que fizemos.

\section{EXPOSIÇÃO À VIOLÊNCIA EM ESCOLAS DE ENSINO MÉDIO DE SÃO RAIMUNDO NONATO, PIAUÍ}

Tentando trazer uma maior contribuição na análise da problemática da violência escolar em geral e do bullying em particular, à luz da discussão conceitual exposta, fizemos uma observação preliminar de situações de agressões e intimidações praticadas ou sofridas por estudantes de ensino médio na cidade de São Raimundo Nonato, Piauí. Por meio de um questionário online, elaborado a partir da plataforma de questionários do Google, estudantes das cinco escolas de ensino médio da cidade responderam 23 questões sobre o tema, entre os dias 12 e 16 de janeiro de 2018. Dessas instituições, quatro são públicas e uma privada.

Participaram da pesquisa 112 estudantes com idade entre 13 e 27 anos, tendo a maior concentração na faixa dos 16 (40,2\%). Na divisão por sexo foram 77 mulheres e 35 homens (gráfico 1), distribuídos do $1^{\circ}$ ao $4^{\circ}$ ano do ensino médio (gráfico 2). Apesar de constituir-se uma amostra aleatória, buscamos contemplar uma diversidade de sexo, de idade, de série e de instituição. Mais de $75 \%$ dos entrevistados consideram que seu rendimento escolar até o momento é bom ou ótimo.

Gráfico 1: sexo

Gráfico 2: série

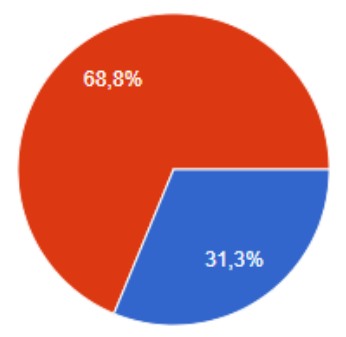

Fonte: próprio autor, 2018.
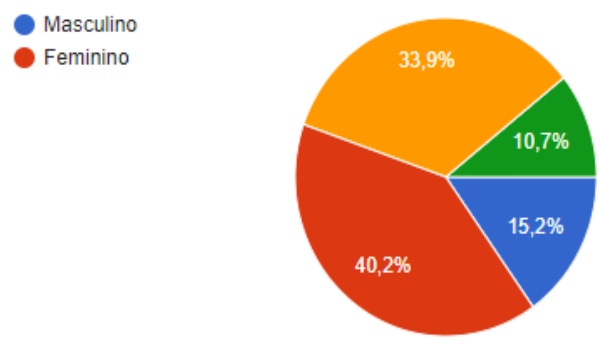

Fonte: próprio autor, 2018. 
Tentando diagnosticar o grau de integração e acolhimento, questionamos sobre suas relações com colegas, professores e demais funcionários. Questionados sobre $o$ acolhimento por parte dos professores, a maioria $(51,8 \%)$ respondeu que eles são acolhedores, seguidos de muito acolhedores (33,9\%), pouco acolhedores $(10,7 \%)$ e indiferentes $(3,6 \%)$. Quanto aos demais funcionários da escola, também a maioria afirmou que são acolhedores (61,6\%), seguidos de muito acolhedores $(20,5 \%)$, pouco acolhedores (12,5\%) e indiferentes (5,4\%). Com relação à percepção de integração com os colegas de classe, $52,7 \%$ afirmou estar muito integrado, 31,3\% integrado, 12,5\% pouco integrado e 3,6\% respondeu que prefere não se integrar. As informações sugerem a predominância de ambientes com laços amistosos, com elevado grau de integração entre os discentes.

Quando questionados sobre os tipos de violência presentes nas escolas e o grau de ocorrência, chama atenção que 25,9\% afirmou nunca ter presenciado nenhum tipo de agressão física ou verbal. Do outro lado, 6,3\% disse ter observado agressões com muita frequência. A maioria, $54,5 \%$, respondeu que raramente testemunhou tais fatos.

Respondendo ao papel de agressor, 93,8\% disse nunca ter praticado agressão física na escola, 3,6\% afirmou ter praticado apenas uma vez, 1,8\% duas ou mais vezes e $0,9 \%$ frequentemente. Quanto às agressões verbais, $73,2 \%$ respondeu nunca ter feito, $9,8 \%$ apenas uma vez, $13,4 \%$ duas ou mais vezes e $3,6 \%$ frequentemente. A questão não identificou a quantidade de vítimas, assim, aqueles que frequentemente cometem agressões verbais e/ou físicas podem não se enquadrarem no comportamento típico de bullying, tendo em vista que elas podem ter sido praticadas contra pessoas diferentes. Isso não atenua a agressão e continua caracterizando-se como violência, o que é lamentável, mas não se configura como intimidação sistemática.

Respondendo ao papel de vítima, mesmo que levemente, os números mudam um pouco, demonstrando que há mais vítimas que agressores. Sobre ter sofrido agressão física (gráfico 3), 91,1\% afirmou nunca ter sofrido, 4,5\% apenas uma vez, $2,7 \%$ duas ou mais vezes e 1,8\% frequentemente. Sobre ter sofrido agressão verbal (gráfico 4), 61,6\% disse nunca ter sido alvo, 12,5\% apenas uma vez, 14,3\% duas ou mais vezes e $11,6 \%$ frequentemente. Confirmando o que já foi observado em outras pesquisas aqui citadas, eles responderam que na maioria dos casos $(78,4 \%)$, as 
agressões partiram de colegas de classe, mas também estudantes de outras turmas $(43,1 \%)$. Esses dados revelam que uma vítima pode ter vários agressores, dentro e fora da turma.

Embora em pequeno número, observamos que 1,8\% dos entrevistados afirmou ser vítima de agressão física com frequência. Quanto à agressão verbal, o percentual sobe para $11,6 \%$. Aqui o cenário exige cautela, pois esses estudantes podem estar sofrendo como vítimas de bullying, tendo seus processos de sociabilidade alterados pela violência escolar. Uma análise mais cuidadosa, mais próxima das vítimas, pode fazer a diferença para uma intervenção eficaz e rápida.

\section{Gráfico 3: vítima de agressão física}

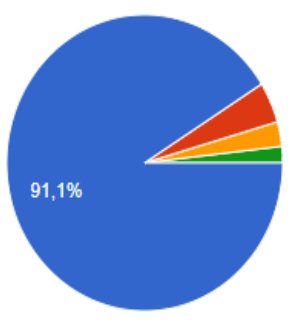

Fonte: próprio autor, 2018.

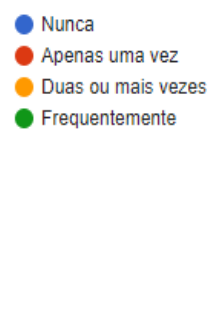

\section{Gráfico 4: vítima de agressão verbal}
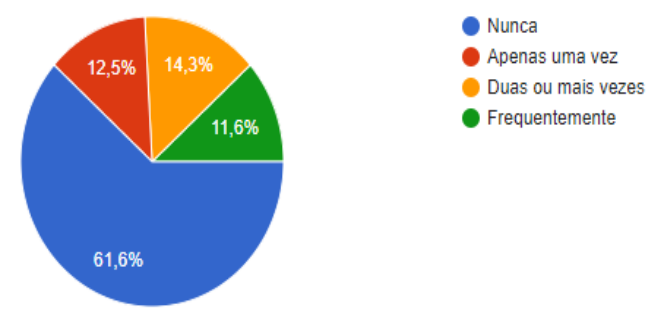

Fonte: próprio autor, 2018.

Segundo as vítimas, as agressões físicas com maior número de ocorrência foram empurrões $(53,6 \%)$ e socos $(25 \%)$. Quanto às agressões verbais com ocorrência mais comum, $46,3 \%$ das vítimas foi alvo de xingamentos e o mesmo percentual de apelidos pejorativos, seguidos de comentários depreciativos $(40,7 \%)$, expressões preconceituosas (22,2\%) e ameaças (9,3\%). Em acréscimo, 25\% de todos os entrevistados afirmou ter sido alvo de isolamento social por parte de colegas.

Perguntamos ainda a que as vítimas atribuíam as agressões e o resultado foi o seguinte: ao porte físico (44,3\%), à outra causa não especificada na enquete $(42,6 \%)$, à orientação sexual $(11,5 \%)$, ao local de moradia ou nascimento $(11,5 \%)$, à cor da pele $(6,6 \%)$, à religião $(4,9 \%)$, ao gênero $(3,3 \%)$ e à condição econômica $(1,6 \%)$. O número expressivo de estudantes que optou por outro motivo pode indicar que eles próprios desconhecem ou realmente são inexistentes, configurando violência gratuita tão presente nos casos de bullying. 
Àqueles que foram vítimas de algum tipo de agressão, perguntamos ainda como foi sua reação diante do/s fato/s. A maioria $(53,1 \%)$ não reagiu de nenhuma forma e $23,4 \%$ afirma ter revidado da mesma maneira. Em ambos os casos temos respostas que podem ser problemáticas. No primeiro, os estudantes podem simplesmente ter ignorado as agressões por não thes ter afetado, mas também podem ter somatizado e sofrido em silêncio. No segundo, temos uma reação também agressiva que pode estimular reações ainda mais violentas agravando o problema. As reações que nos parecem mais assertivas partiram daqueles que buscaram ajuda da escola ou dos familiares, como mostra o gráfico 5. O que nos surpreendeu foi que $63,3 \%$ das vítimas disseram que as agressões não afetaram em nada. Contudo, temos que oferecer ajuda a quem precisa e são aqueles que disseram que a integração com os colegas foi afetada $(26,7 \%)$, as relações extraescolares (18,3\%), a frequência e o rendimento escolar $(6,7 \%)$. Sobretudo para esses estudantes, para seus agressores e os espectadores é que deverão ser dirigidas as ações de combate à violência escolar.

\section{Gráfico 5: reações frente às agressões}

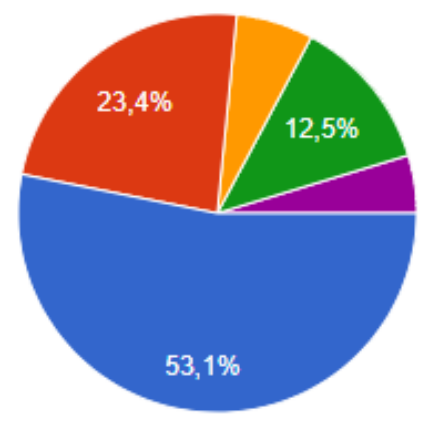

Fonte: próprio autor, 2018.

Por fim, ressaltamos que esta investigação preliminar, embora não apresente um diagnóstico como um mapa da violência nas escolas de ensino médio de São Raimundo Nonato, pode funcionar como um importante termômetro das relações sociais tecidas entre estudantes e funcionários das escolas. O alto grau de integração e o acolhimento certamente contribuem para que as relações amistosas predominem frente às hostis. Investigações mais detalhadas podem acrescentar a 
análise da situação socioeconômica das famílias, da estrutura física da escola, da segurança do entorno, dentre outros.

Mesmo em caráter preliminar, identificamos que alguns alunos sofrem constantes agressões no ambiente que deveria proporcionar um bem estar adequado ao pleno desenvolvimento humano. Também identificamos os principais tipos de abusos, as reações e as consequências. Acreditamos que uma investigação em profundidade qualitativa, baseada em relatos individuais pode explicitar mais questões que contribuam para a implementação das ações de combate ao bullying e outras formas de violência.

\section{CONCLUSÃO}

Mostramos que, como parte de sociedades fragmentadas e conflituosas, a violência escolar tem se manifestado de diversas formas em muitos lugares. Uma de suas manifestações mais complexas e recorrentes, o bullying, ampliou-se em muitas realidades na contramão das políticas voltadas para a inclusão e respeito às diferenças. Tais atitudes, como argumentamos, dificultam 0 processo de aprendizagem, o desenvolvimento pleno das habilidades cognitivas e provocam danos físicos e psicológicos aos envolvidos.

A criação de relações sociais fortes, mais dialógicas e fomentadoras do respeito mútuo estão na base da prevenção e combate ao fenômeno. A escola deve desempenhar um papel fundamental para isso. Contudo, é necessário que a instituição escolar atue em parceria com as famílias e com todos os setores da sociedade que lutam para diminuir a violência, como Conselhos Tutelares, Associações de bairros, juizados, dentre outros. Reconhecer a existência do problema é o primeiro passo, mas é preciso capacitação dos profissionais da educação e articulação em rede para que as medidas tomadas sejam eficazes.

O protagonismo dos alunos se faz necessário para encontrar saídas efetivas em relação às situações que eles mesmo vivenciam cotidianamente. À medida que a comunidade educativa (estudantes, pais ou responsáveis, professores e demais funcionários) construa ferramentas contando com os envolvidos, as relações sociais podem se fortalecer, fazendo de todos coparticipantes e responsáveis na resolução dos problemas. 
Em situações mais graves, onde as medidas escolares de combate às formas variadas de violência não surtirem efeito, recomenda-se a adoção das medidas legais a exemplo das previstas no Estatuto da Criança e do Adolescente, no Código Civil e no Código Penal, de modo que esses fatos não continuem sendo considerados brincadeiras e as agressões banalizadas enquanto as vítimas se enfraquecem e os autores se fortalecem.

\section{REFERÊNCIAS}

ABRAMOVAY, Miriam. (Coord.). Diagnóstico participativo das violências nas escolas: falam os jovens. Rio de Janeiro: FLACSO - Brasil, OEI, MEC, 2016.

BERNARDO, André. BBC Brasil. De notas baixas a depressão na vida adulta, as marcas do bullying em agredidos e agressores Disponível em: http://www.bbc.com/portuguese/brasil-41689223 Acesso feito em 13 de janeiro de 2018.

BRASIL. Constituição da República Federativa do Brasil. Brasília, 1988. Disponível em: http://www.planalto.gov.br/ccivil 03/constituicao/constituicaocompilado.htm Acesso feito em 16 de janeiro de 2018.

Lei 8.069 de 13 de julho de 1990. Estatuto da Criança e do Adolescente. Brasília, 1990. Disponível em: http://www.planalto.gov.br/ccivil 03/leis/L8069.htm Acesso feito em 16 de janeiro de 2018.

. Lei 9.394 de 20 de dezembro de 1996. Lei de Diretrizes e Bases da Educação Nacional. Brasília, 1996. Disponível em: http://www.planalto.gov.br/ccivil 03/leis/L9394.htm Acesso feito em 16 de janeiro de 2018.

. Lei 13.185 de 6 de novembro de 2015. Institui o Programa de Combate à Intimidação Sistemática. em: http://www.planalto.gov.br/ccivil 03/ ato2015-2018/2015/lei/l13185.htm Acesso feito em 16 de janeiro de 2018. 
DIAS, Fabiana Bruna Gozer e PINGOELLO, Ivone. Bullying na Educação Inclusiva. Revista de Educação do Vale do Arinos, Juara/MT/Brasil, v. 3, n. 1, jan./Jul. 2016, p. 40-54.

MARTÍNEZ, José Maria Avilés. Bullying: guia para educadores. Tradução de J. Guillermo Milán-Ramos. Campinas: Mercado de Letras, 2013.

SILVA, Ana Beatriz Barbosa. Bullying: mentes perigosas nas escolas. Rio de Janeiro: Objetiva, 2010.

VIEIRA, Vanessa Alves et al. Gênero e diversidade sexual nas escolas: uma questão de direitos humanos. Carta Capital, 2015. Disponível em:

https://www.cartacapital.com.br/sociedade/genero-e-diversidade-sexual-nas-escolasuma-questao-de-direitos-humanos-6727.html Acesso feito em 16 de janeiro de 2018. 